\title{
As redes de conhecimento: uma canção em várias vozes
}

\section{Knowledge networks: one song, many voices}

Gardia Vargas é doutoranda em Educação pela Universidade Federal do Rio Grande do Sul (UFRGS).

Contato: gardia.vargas@terra.com.br

Paulo Sergio Fochi é mestre em Educação, com bolsa do CNPq, pela Universidade Federal do Rio Grande do Sul (UFRGS).

Contato: paulo.fochi@yahoo.com.br

\section{Resumo}

Este artigo apresenta o relato de uma experiência de duas escolas de educação infantil do Rio Grande do Sul na busca de práticas capazes de garantir a participação das crianças em projetos pedagógicos. Denominada rede de conhecimento e baseada em mapas conceituais, a modalidade de trabalho em pauta é permeada por ideias de escuta, narratividade e documentação pedagógica. Tal prática, realizada com crianças de 0 a 6 anos, possibilita um diálogo entre conceitos da sociologia da infância e da pedagogia da infância. Além disso, aborda a dimensão formativa de professores e contribui para reflexões acerca da docência na educação infantil'.

Palavras-chave: educação infantil; participação; documentação; narratividade.

\section{Abstract}

This article presents a record built on an experience acquired at two early childhood education schools during the quest for practices that would guarantee children's participation

1. Uma versão preliminar do presente artigo foi apresentada em 2012 pelos autores no VI Congresso Paulista de Educação Infantil (COPEDI) e II Congresso Internacional de Educação Infantil "Educação Infantil subvertendo ordens? Política, imaginação e fantasia". 
in their own pedagogical projects. Named as knowledge networks and based on concept mapping, the technique is permeated by ideas of listening, narrative and pedagogical documentation. This practice, carried out with children aged 0 to 6 years old, enables a dialogue between the concepts of sociology of children and childhood pedagogy. It also discusses the dimension of teachers' formation and contributes for further reflection on early childhood education teaching.

Keywords: early childhood education; participation; documentation; narrative.

\section{0 prelúdio desta canção}

0 presente texto apresenta uma experiência com projetos pedagógicos que vem sendo desenvolvida em duas escolas de educação infantil no Rio Grande do Sul. Ambas as instituições são da rede privada, sendo uma localizada no município de Porto Alegre e a outra, em Veranópolis. Embora situadas em contextos distintos, elas nutrem desejos semelhantes: um deles é tornar possível a participação das crianças na arquitetura de projetos pedagógicos do cotidiano da escola. ${ }^{2}$

A partir dessa motivação equivalente, o presente texto trata de uma experiência fomentada pelo desejo que sempre ressoou nas formações de professores e nas reuniões entre coordenadores: a possibilidade de dar voz às crianças na construção e na narração dos projetos didáticos. Porém, preocupados com o fato de que alguns discursos naturalizam determinadas práticas - tal como ocorre com esse de dar voz às crianças -, nosso objetivo foi, em grande parte, realizar mudanças nessa realidade de modo a provocar um real envolvimento e uma real participação das crianças.

Devido a isso, buscávamos transpor a barreira do instituído narrado, mas não realizado. Um movimento como esse não é nada fácil, porém, é necessário no cotidiano das escolas infantis, visto que as crianças têm o direito a participar e manifestar seus desejos por meio de suas múltiplas formas de se comunicar e de estabelecer relações com o mundo. Assim, ao observar as ações das crianças, suas linguagens e seus movimentos no cotidiano das

2. Os autores do texto são coordenadores pedagógicos e trabalharam juntos na escola de Porto Alegre. escolas, questionávamo-nos sobre quais seriam as formas reais de possibilitar a participação delas. 
O fenômeno da participação da criança na escola não é novo: constitui-se como uma das mais reivindicadas dimensões do discurso pedagógico da Modernidade. No entanto, o respeito à criança e à sua participação na escola está longe de ser uma realidade, já que o suporte em nível social e político para que isso aconteça não tem tido apoio e tampouco se encontra contemplado na cultura escolar. A participação das crianças na educação é uma discussão que vem ganhando força nos estudos da sociologia da infância e na abordagem das pedagogias da infância. Contudo, ainda não se traduz em prática.

A participação efetiva de meninos e meninas na ação pedagógica é uma estratégia pensada como respeitosa aos sujeitos envolvidos no ato educativo. Ademais, essas práticas que têm como princípio condutor do trabalho o protagonismo das crianças precisam instaurar uma observação e uma escuta atentas aos modos próprios como elas comunicam seus pontos de vista. Para tanto, necessitam de sensibilidade, compromisso e conhecimentos por parte dos professores acerca das crianças, a fim de que estas possam apreender todos os conteúdos trabalhados.

Tais conteúdos se expressam de cem formas (MALAGUZZI, 1999) e, por isso, envolvem a dimensão corporal, o afeto, as culturas infantis e a produção cultural das crianças, sugerindo modos de participação em seus contextos de vida. Conforme apontam Vargas e Martins (2011), o importante é entender o que a criança expressa sobre si, os outros e o mundo em que vive. Assim, é preciso estar atento para observar o que ela faz, sobre o que conversa e do que brinca nos diferentes espaços e tempos do contexto escolar.

Nesse sentido, com o intuito de desenvolver uma prática que tornasse concretos e visíveis os interesses e as ideias das crianças, elaboramos um trabalho pedagógico a fim de permitir que todos os envolvidos nos processos de aprendizagem tivessem visibilidade, percebendo e produzindo seus conhecimentos por meio da narrativa. Se, por um lado, já havíamos avançado significativamente nas duas escolas ao estabelecer o surgimento dos projetos de trabalho (ou pedagógicos) 3 a partir das demandas das crianças, por outro, ainda nos custava caro compreender as possibilidades de elas narrarem seus percursos e se perceberem como parte ativa de todo o processo.

Convictos de que participar, além de falar e ser ouvido, consiste em tomar decisões e nortear o caminhar do trabalho, buscávamos, nas reflexões ocorridas durante os processos de formação, construir uma narrativa coletiva - entre educadores
3. O método de projetos foi criado pelo norte-americano William Kilpatrick (1871-1965) com base nas ideias de John Dewey (18591952), sobretudo em seus estudos acerca de uma escola ativa. Em setembro de 1918, uma das mais importantes revistas de educação, Teachers College Recort, divulgou um artigo no qual o autor explica e denomina seu método. A proposta caracteriza-se como uma forma de integração curricular e preocupa-se com o interesse que deve acompanhar o trabalho pedagógico de modo a suscitar no aluno a vontade de saber. 
e crianças - sobre como os projetos de estudo se desenvolviam. Até o momento em que se iniciaram as atividades com as redes de conhecimento, os projetos de trabalho eram elaborados pelas professoras, que costumavam questionar formalmente as crianças sobre o que elas gostariam de estudar.

Porém, essa prática de fazer perguntas relativas ao que se deseja estudar se mostrava pouco eficiente, sobretudo por demandar que os professores interpretassem as distintas manifestações das crianças e, à luz do contexto, lançassem mão de proposições, até mesmo no caso dos alunos que não dominam a linguagem oral, mas que se comunicam e se relacionam com o mundo.

Também foi necessário mudar a perspectiva dos adultos para dar voz às crianças. Partimos para formações e reflexões que possibilitassem aos professores o acesso às múltiplas linguagens das crianças para que, dessa forma, junto a elas e com elas, eles pudessem vislumbrar os interesses narrados por meio do corpo, do brincar, dos materiais, das escolhas que faziam e do que solicitavam em suas interações.

Outro aspecto importante de nossas ações dizia respeito à forma como as crianças participariam não apenas no surgimento dos projetos, mas também em todo o desenvolvimento destes, inclusive podendo determinar os rumos que os planos tomariam a partir da participação coletiva e cooperativa de todos os envolvidos. Tínhamos a convicção de que, assim como as crianças eram capazes de motivar a elaboração de projetos surpreendentes, elas também poderiam construir narrativas a respeito das experiências que tais projetos lhes proporcionavam.

No entanto, sabíamos que, para dar voz a esse canto e fazêlo ressoar, seria preciso criar instrumentos que auxiliassem na organização, na dinâmica e no registro dos percursos dos projetos. Em razão disso, outro aspecto tangenciava o processo: a articulação entre os projetos e a forma como os registraríamos, compartilharíamos com as famílias e nos utilizaríamos de tal instrumental para construir os portfólios de aprendizagem das crianças. Essa prática precisava estar entrelaçada e significada em sua totalidade para todos os atores envolvidos - crianças, professores, famílias e escola -, um coletivo que constrói junto o processo de conhecer e dá significado aos percursos trilhados.

Com base nesse viés, estávamos preocupados em como documentar e dar visibilidade às crianças sobre todo o 
desenvolvimento de seus projetos de estudo. Em tal cenário, temas muito pontuais surgiram a partir da observação das crianças e de suas falas durante os momentos de partilha e brincadeira. Conversar e brincar com elas vai além de observá-las; trata-se de um estar com para construir junto uma prática compartilhada.

Segundo Vargas e Martins (2011), na escola, as crianças diariamente criam sentidos e atuam ativamente sobre o que vivenciam, produzindo conhecimentos relativos a elas próprias, ao mundo e aos outros. Diante disso, é preciso problematizar as formas como a escola lida com as ações das crianças, e cabe lançarmos o seguinte questionamento: qual é a importância dos conhecimentos que as crianças levam para a escola e que lugar eles ocupam nas práticas educativas?

Foi na busca por reconhecer essa forma de ver a criança e de conceber a infância que desenvolvemos as atividades com as redes de conhecimento. Tal plano de trabalho ganhou esse nome devido a uma experiência realizada na escola de Bento Gonçalves, onde um menino de 5 anos, Pedro, intitulou os registros feitos e fixados na parede partindo da lógica que estabeleceu com uma rede de goleira de campo de futebol: "que legal filho, esse painel é sobre o projeto da tua turma? Isso não é um painel, é uma rede de conhecimento. Que nem a rede de futebol. Só que nessa rede tem coisas sobre o circo" (FOCHI, 2011b, p. 20).

Vale também salientar que, para a efetivação dessa metodologia que proporíamos, baseamo-nos em alguns estudos publicados por autores que utilizavam mapas mentais ou conceituais no trabalho com crianças, tais como Silva e Geller (2007), Tavares (2007) e Mograbi (2007).

No que tange ao seu desenvolvimento, o projeto aconteceu de forma ampla, envolvendo todos os níveis da escola, desde os bebês de 0 anos até as crianças das turmas de jardim, de 4 e 5 anos. Ao longo de todos os processos, refletimos, conjuntamente com as professoras sobre como poderíamos trabalhar em uma perspectiva que considerasse a criança como um ser de direito, que não é passivo perante sua cultura e que aprende no coletivo ao participar, conversar, cantar, pintar, brincar, entre outras atitudes, por meio de suas múltiplas formas de se comunicar e de se relacionar com o mundo.

Ainda no que se refere ao estímulo para a participação das crianças, primeiramente precisamos entender que, considerando que as crianças têm pontos de vista diferentes dos adultos, 
necessitamos valorizar seus conhecimentos dentro do contexto escolar, em um exercício de escuta atenta e afetuosa. Isso se configura em uma aproximação do mundo infantil e em uma valorização daquilo que a criança nos comunica a partir de suas diferentes linguagens. É importante ressaltar que a escuta à qual nos referimos aqui é fruto do inesperado e, portanto, do inédito.

Assim, não nos cabe desejar escutar as crianças se, ao mesmo tempo, supomos o que elas querem nos dizer. Ao contrário, escutar implica um abandono, por parte do adulto, de suas verdades e de seus modos de perceber o mundo, valorar e consolidar percursos. Nessa perspectiva, a escola deve ser um lugar de convivência, onde os diferentes percursos de todos os envolvidos se consolidem em conteúdos e aprendizagens, um lugar em que as crianças “[...] cresçam como pessoas que se aceitam e se respeitam, aceitando e respeitando outros num espaço de convivência em que os outros aceitam e respeitam a partir do aceitar-se e respeitar-se a si mesmo" (MATURANA, 2009, p. 30). Por fim, foi na busca por consolidar todos os princípios supracitados que se desenvolveu o trabalho com as redes de conhecimento.

\section{Redes de conhecimento: uma construção da narrativa coletiva}

Rede, como o próprio nome indica, é também uma reivindicação à dimensão de conhecimento - ou melhor, à dimensão de conhecer $^{4}$ - a fim de que os limites que dividem uma ou outra área possam ser entoados em comunhão: uma construção que possibilita desabar as fronteiras entre saberes e disciplinas, bem como desnaturalizar certas pressuposições norteadoras do pensamento científico ocidental, que opõe o biológico ao social ou cultural. Tal premissa dualista, que reaparece sob formas variadas - corpo x mente, natureza x história, indivíduo x sociedade -, encontra-se nos musculosos 5 aparatos didático-pedagógicos, conforme lembra Fortunati (2009).

Para que o trabalho com as redes se efetivasse, a primeira etapa foi investir na formação docente, problematizando, junto ao grupo de professoras, a forma como poderíamos construir essa prática a partir de uma lógica que convertesse as crianças em protagonistas de todo o percurso de aprendizagem construído com o estudo do projeto. Em seguida e aos poucos, à medida que os projetos de cada turma surgiam, conceitos foram sendo fixados nas paredes das salas e ampliando-se de forma processual. Assim se estruturaram as redes entre os saberes e os fazeres dos projetos das crianças.
4. A opção pelo verbo conhecer em vez do substantivo conhecimento deriva da compreensão de que as práticas pedagógicas na educação infantil devem estar permeadas pela dimensão da experiência, de modo que os começos e términos desapareçam e deem lugar à possibilidade de interpelar o mundo constantemente. Portanto, interessa-nos falar em processos do conhecer e não no produto conhecimento.

5. Fortunati (2009) utiliza a expressão musculosos aparatos didáticos para os tantos artefatos presentes na tradição da escola (planejamento, currículo, avaliação), artefatos dos quais ela tem muita dificuldade para se livrar e, assim, repensar sobre outras formas de organizar seu cotidiano. 
As temáticas dos projetos sempre partem de perguntas que extraídas de temas de interesse das crianças, sendo, muitas vezes, até mesmo elaboradas por elas. São exemplos de tais perguntas: por que os dentes caem? (jardim - 4 anos); como surgiram as letras? (jardim - 5 anos); com que roupa eu vou? (maternal - 3 anos); como se chega à África? (maternal - 3 anos, no contexto da Copa do Mundo); para onde o sol vai quando chega a noite? (maternal - 3 anos); quem pintou o arco-íris no céu? (maternal -2 anos).

Os registros feitos nas redes de conhecimento partem de centros - as perguntas das crianças - a partir dos quais são irradiadas as informações relacionadas. Tais pontos-chave podem ser elaborados por meio de canetas coloridas sobre folhas de papel ou de imagens e fotografias que permitem a leitura das crianças. Essas redes, seguindo a mesma lógica dos mapas conceituais ou mentais, são úteis não apenas para documentar o projeto e dar visibilidade ao seu andamento, mas também para registrar de forma produtiva as ideias e hipóteses das crianças acerca do que está sendo estudado no projeto. Isso permite revisões rápidas dos assuntos compreendidos em forma de resumos, os quais sintetizam o entendimento dos percursos e das descobertas proporcionadas pelo projeto ao grupo.

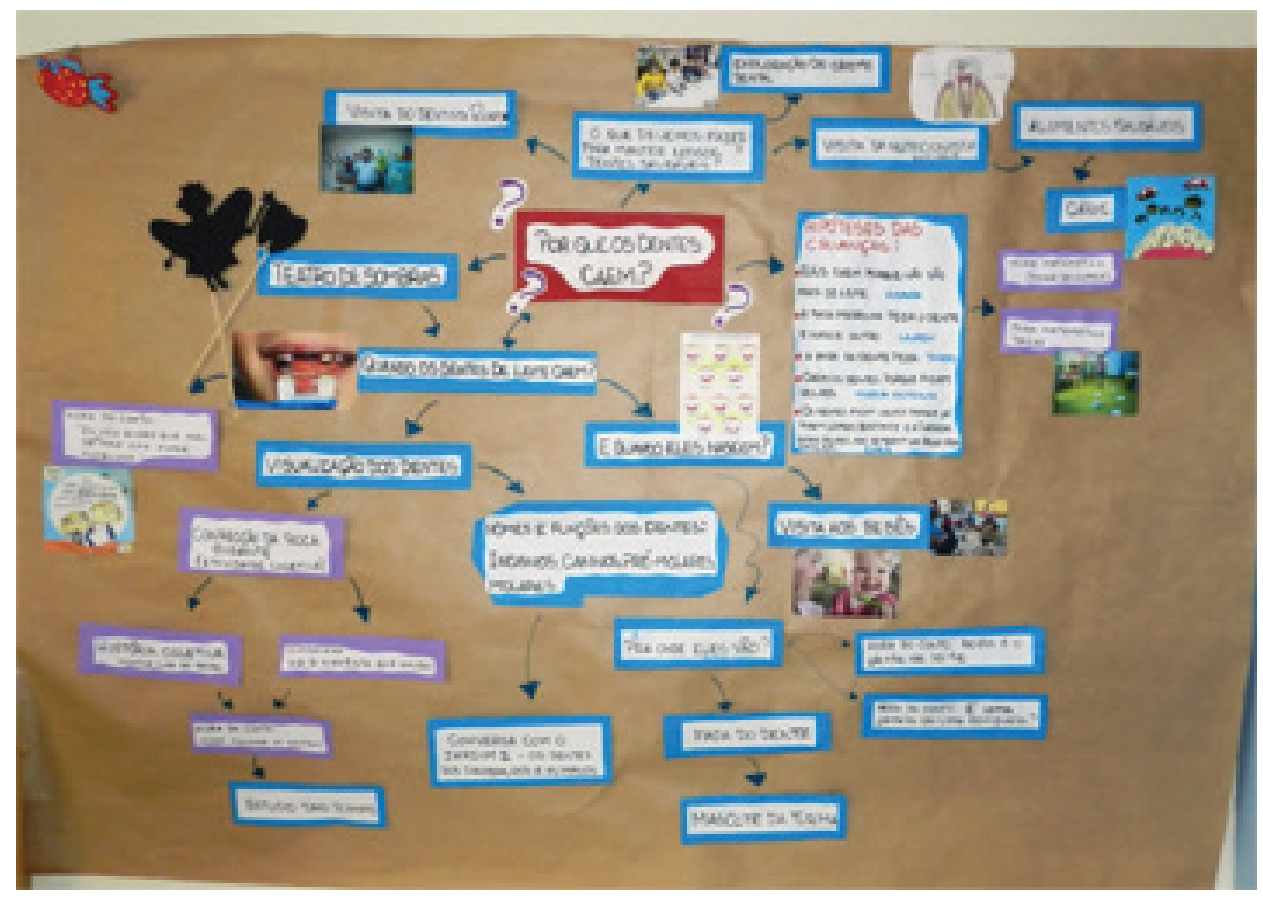

Figura 1 - Rede de conhecimento

Perguntas como as anteriormente mencionadas serviram de enredo para os projetos de estudo das turmas; a partir delas, 
outras perguntas eram abertas e contempladas no percurso. Ao longo do projeto, a professora retomava com as crianças a pergunta inicial, a fim de avaliar com os alunos se o percurso feito auxiliava a respondê-la. Assim, crianças e adultos, conjuntamente, narravam saberes, fazeres, histórias, desejos e hipóteses sobre o que estavam estudando. Durante a narrativa que surgia a partir do que estava estruturado nas redes de conhecimento por meio de imagens, amostras de trabalhos das crianças e outros itens, meninos e meninas indicavam novas hipóteses, novos caminhos e novas perguntas.

Com base nas perguntas registradas e no suporte de imagens que permitiam às crianças participar da leitura, fomos percebendo como as redes de conhecimento ampliavam as possibilidades de compreensão e apreensão dos conteúdos abordados, desdobrando-se, de forma natural, em uma solicitação para que outras vozes participassem desse canto. Nas saídas e chegadas das crianças à escola, não era raro encontrarmos pais e filhos em frente às redes, conversando sobre os percursos realizados. Com isso, um convite aos pais era acordado, sem que ninguém precisasse fazê-lo: a participação nos projetos envolvia não só crianças e professores, mas também pais, irmãos, avós. Os projetos, por sua vez, atravessavam as casas das famílias já não mais como uma preparação para a vida, mas como a própria vida.

Assim, destacamos que, para além de uma modalidade de registro, a prática com as redes de conhecimento impulsionou:

- O envolvimento das famílias e a ampliação de sua contribuição com o percurso de seus filhos na escola;

- A ampliação e enriquecimento das narrativas infantis: entre elas e com os adultos;

- A documentação do trabalho pedagógico;

- Um formato de trabalho onde o planejamento e os projetos de trabalho eram decididos coletivamente: professores, crianças, famílias e demais profissionais da escola. (FOCHI, 2011b, p. 22)

Antes de darmos continuidade e para que este texto represente sumariamente o processo de construção das redes, que não é linear, retomamos rapidamente o início do trabalho junto às professoras. Ao iniciarmos essa modalidade de ação na escola, convidamos as professoras a construírem narrativas de seus 
percursos pessoais utilizando imagens e pequenas frases ou palavras.

Durante o processo de organização das trajetórias pessoais, as docentes se defrontaram com a necessidade de subverter a linearidade dos caminhos e começar novas ramificações, tal como a própria dinâmica da vida. Esses trajetos bifurcados e rizomáticos auxiliam a compreender que os percursos nem sempre se encerram, mas podem ficar abertos. Além disso, os ritmos de vida variam e pulsam em diferentes modos de estar e relacionar-se com ela, demarcando processos que nem sempre são lineares.

Após essa experiência, alguns encontros foram dedicados a estudos e debates sobre as redes de conhecimento e, a partir de então, cada professora iniciou a construção de redes com seu grupo de alunos. Isso porque se entendeu que, dada a natureza dessa modalidade pedagógica, o trabalho se constitui em sua própria construção. Tanto as professoras quanto a equipe de coordenação não sabiam ao certo quais seriam as etapas do trabalho; como todos haviam sido alunos de escolas pautadas em pedagogias diretivas, em que o objetivo era o domínio do que seria proposto ou da necessidade de intervir, a imprevisibilidade presente nas redes de conhecimento e o deslocamento da figura do adulto assustou a todos.

No entanto, conforme o tempo foi passando, descobrimos que a imprevisibilidade característica de tal modalidade, devido ao seu formato de registrar e narrar os percursos, nada mais é do que um reflexo da complexa relação do ser humano com o mundo. ${ }^{6}$ Utilizando como metáfora a composição de uma música, em que os instrumentos são, pouco a pouco, escritos na partitura, as redes de conhecimento ressoam em uma música também de diversos instrumentos, timbres, nuances e intensidades. Nessa modalidade de trabalho, crianças, professores e pais participam, democraticamente, tanto no que diz respeito ao acompanhamento da prática quanto no que se refere às decisões a serem tomadas.

\section{Da intenção à ação: redes de conhecimento e a possibilidade de documentar percursos}

Documentar o trabalho pedagógico é uma importante prática para o professor, a criança, a família e a escola na educação infantil. Tal prática se caracteriza como um processo de registro, avaliação do trabalho pedagógico, desenvolvimento infantil e aprendizagem. As possibilidades presentes na documentação
6. Diversos autores destacam a importância de refletirmos sobre a condição do inesperado. Hannah Arendt (2005) nos ajuda a pensar tal aspecto ao tratar da ação e do discurso; Loris Malaguzzi (1999), por sua vez, em sua pedagogia para a infância, afirma que só é possível escutarmos as crianças se definitivamente assumirmos que o inesperado é da gênese humana e que, portanto, escutar as crianças implica refletir sobre aquilo que nos escapa. 
pedagógica são inúmeras e relevantes para que se conheçam os modos e as ações das crianças nos espaços coletivos. Porém, faz-se necessária a superação de uma visão superficial acerca do que é e para que serve a documentação pedagógica.

A importância da documentação se justifica na busca por uma prática docente que tenha como objetivo dar visibilidade a várias formas de compreender a criança, suas realizações e seus processos de aprendizagem durante o trabalho educativo. Outro aspecto fundamental é a possibilidade de participação direta das crianças no ato de documentar, o que dá visibilidade às escolhas que elas fazem quando narram seus percursos.

0 trabalho aqui apresentado viabilizou maneiras de realização dessa prática e ofereceu às crianças e às suas professoras a oportunidade de praticarem o registro e a documentação de forma coletiva e estruturada. Sempre disponíveis e atentas, as professoras fizeram o exercício de uma escuta cuidadosa e sensível ao que as crianças comunicam em suas vivências coletivas, construindo uma cultura própria da infância.

A documentação pedagógica representa para o professor uma forma relevante de concretização e aperfeiçoamento do trabalho docente; além disso, como ampliação dos espaços de aprendizagem e desenvolvimento das crianças, ela serve para conhecer seus modos de ser e agir em espaços coletivos. Apresenta, ainda, diferentes aspectos que contribuem para a promoção do trabalho realizado pela instituição. Como principal finalidade, deve-se colocar a criança no centro de todo o projeto educativo, dando visibilidade às suas aprendizagens e vivências. Tal prática também exerce um papel relevante ao se configurar como fonte informacional para os envolvidos no trabalho educativo e para a comunidade escolar.

Outro importante aspecto do registro na educação da infância diz respeito ao fato de que, quando documentamos, estamos tornando visível o processo, mudando o foco do resultado para o percurso que levou à aprendizagem. Dessa forma, o registro está intimamente ligado à avaliação e ao acompanhamento do desenvolvimento da criança, possibilitando uma melhor percepção dos progressos, obstáculos e limites. Ademais, o ato de documentar permite efetuar intervenções imediatas, apontando possíveis encaminhamentos.

No decorrer do trabalho, ao construir as narrativas por meio das redes de conhecimento, a documentação também se consolida como um espaço de pesquisa e busca de respostas, um momento de aprendizagem do professor perante as crianças, ao perceber as 
apropriações feitas por elas no desenrolar do projeto educativo. Tanto as crianças quanto os adultos precisam que a vida seja narrada: somos constituídos pelas narrativas que nos são apresentadas ao longo de nossa existência. Assim, podemos entender o trabalho com as redes de conhecimento como "uma possibilidade de registro que autoriza e convida para que o adulto abra um campo extenso na elaboração das narrativas, para combinar conhecimento, realidade e ficção, uma relação necessária para a nossa condição humana" (FOCHI, 2011a, p. 41).

Concluímos, portanto, que oportunizar às crianças a participação em suas próprias aprendizagens requer investimento, observação atenta e, mais do que isso, a postura de estar junto para construir coletivamente as aprendizagens. Entendemos que isso se torna possível a partir da escuta do outro, na presença atenta e sensível que sempre reconhece a importância de estar junto e partilhar experiências.

As crianças que fazem parte do cotidiano aqui narrado constroem seus aprendizados coletivamente e produzem, a cada rede de conhecimento que elaboram, novas formas de perceber o mundo. Tal como nos lembra Mèlich (2010, p. 14, grifo nosso), é preciso perceber que "a vida é uma poética de nome próprio, a narração de um trajeto que nunca se tem recorrido antes, nem tampouco, jamais poderá voltar a recorrer".

\section{REFERÊNCIAS}

ARENDT, Hannah. A condição humana. 10. ed. Rio de Janeiro: Forense Universitária, 2005.

FOCHI, Paulo Sergio. Inventariar ações: as experiências dos bebês em espaços coletivos. Projeto de dissertação de mestrado. Porto Alegre, 2011 .

Redes de conhecimento e as crianças narrando suas aprendizagens. Pátio Educação Infantil, Porto Alegre, n. 29, p. 20-23, out./dez. 2011b.

FORTUNATI, Aldo. A educação infantil como projeto da comunidade. Porto Alegre: Artmed, 2009. 
MALAGUZZI, Loris. Histórias ideias e filosofia básica. In: EDWARDS, Carolyn; GANDINI, Lella; FORMAN, George. As cem linguagens da criança. Porto Alegre: Artes Médica, 1999. p. 59-104.

MATURANA, Humberto. Emoções e linguagem na educação e na política. Belo Horizonte: Editora UFMG, 2009.

MÈLICH, Joan-Carles. El outro de sí mismo. Barcelona: UOC, 2010.

MOGRABI, Adriana Rocha. Mapa conceitual como recurso didático: um relato de experiência na pós-graduação em psicopedagogia. In: CONGRESSO CIENTÍFICO DA UNIVERCIDADE, 2., 2007, Rio de Janeiro. Anais... Rio de Janeiro: UniverCidade, 2007.

SILVA, Márcio Roberto Machado da; GELLER, Marlise. 0 uso dos mapas conceituais com crianças: instrumento para a aprendizagem de ciência. In: ENCONTRO NACIONAL DE PESQUISA EM EDUCAÇÃO EM CIÊNCIAS, 6, 2007, Florianópolis. Anais... Florianópolis: ABRAPEC, 2007.

TAVARES, Romero. Construindo mapas conceituais. Ciência e Cognição, Rio de Janeiro, n. 12, p. 72-85, 2007.

VARGAS, Gardia Maria Santos; MARTINS, Altino José. A organização do trabalho pedagógico respeitando a diversidade e os direitos das crianças. In: BARBOSA, Maria Carmem; FERNANDES, Susana. Diversidade no ambiente escolar: ênfase na educação de crianças de 0 a 10 anos. Porto Alegre: Evangraf/UFRGS, 2011, p. 189-209.

Recebido em: 06/02/2013 Revisado em: 21/03/2013 Aprovado em: 26/03/2013 